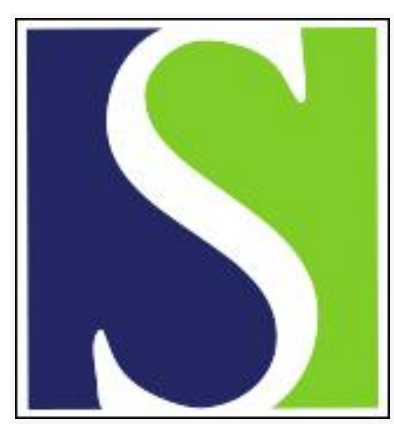

Scand J Work Environ Health 1992;18(3):195-200

https://doi.org/10.5271/sjweh.1588

Issue date: 01 Jun 1992

Effects of perceived job stress on depressive symptoms in blue-collar workers of an electrical factory in Japan.

by Kawakami N, Haratani T, Araki S

Affiliation: Department of Public Health, Faculty of Medicine, University of Tokyo, Japan.

This article in PubMed: www.ncbi.nlm.nih.gov/pubmed/1615294

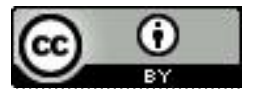




\title{
Effects of perceived job stress on depressive symptoms in blue-collar workers of an electrical factory in Japan
}

\author{
by Norito Kawakami, MD, ${ }^{1}$ Takashi Haratani, DHSc, ${ }^{2}$ Shunichi Araki, MD ${ }^{1}$
}

\begin{abstract}
KAWAKAMI N, HARATANI T, ARAKI S. Effects of perceived job stress on depressive symptoms in blue-collar workers of an electrical factory in Japan. Scand J Work Environ Health 1992;18:195-200. This three-year prospective study on the effects of job stress on depressive symptoms over time was conducted among male blue-collar workers in an electrical factory in Japan. Data were collected at yearly intervals by means of postal questionnaires. Initially ten job stress variables, five major covariates, and depressive symptoms (Zung Self-Rating Depression Scale) were measured. In the yearly examinations, depressive symptoms were measured for a total of 468 respondents. The results indicated that job unsuitability was a significant predictor of depressive symptoms in the second and third year, after control for the initial covariates and depressive symptoms. Lack of control over workpace and poor human relations at the workplace were significantly associated with depressive symptoms after one and two years, respectively. Job unsuitability and poor human relations at the workplace seem to be risk factors for longlasting depressive symptoms in Japanese blue-collar workers.
\end{abstract}

Key words: depression, factory workers, follow-up, Japanese, longitudinal studies, men, occupational stress, psychological tests.

Depressive symptoms have been employed in industrial settings as a useful measure of the mental health and well-being of workers $(1,2)$. In the last decade, many studies have shown that job stress is associated with depressive symptoms among workers (3-9). Selfreported measures of depressive symptoms do not always indicate the presence of clinical depression, however, and in recent years have been considered as measures of nonspecific psychological distress $(10,11)$. But they still seem to be a convenient and useful measure of psychological outcomes vis-á-vis job stress.

Previous investigators have reported that, in general, two groups of job stressors strongly correlate with depressive symptoms. The first group is related to job role or job content, such as role ambiguity $(3,4)$, underutilization of skills, inadequate resources, ambiguity about the future, and nonparticipation in decision making (3). The second group consists of human relations at work (ie, social support from supervisors and co-workers) $(4,8)$. On the other hand, in these studies, job overload or job complexity was only weakly or not significantly correlated with depressive symptoms. Karasek (6) has pointed out that high job demand without autonomy is more important in predicting depressive symptoms than job demand itself. In a recent study by Billings \& Moos (7), the correla-

\footnotetext{
1 Department of Public Health, Faculty of Medicine, University of Tokyo, Japan.

2 National Institute of Industrial Health, Ministry of Labour, Japan.
}

Reprint requests to: Professor S Araki, Department of Public Health, Faculty of Medicine, University of Tokyo, 7-3-1 Hongo, Bunkyo-ku, Tokyo 113, Japan. tions of depressive symptoms with work involvement and poor support from superiors and co-workers were somewhat greater than the correlation with work pressure, although all the correlations were significant. These findings suggest that stressors related to job role or content and poor human relations at the workplace rather than job overload are important risk factors for depressive symptoms in industrial workers. These findings are consistent with those of a report by House (12) in which perceived work rewards were significantly related to neurotic symptoms while quantitative overload was not.

Most of these studies were cross-sectional, and thus the direction of the observed associations is still not clear. In his six-year follow-up study Karasek (6) showed that an increase in job strain was significantly associated with an increase in depressive symptoms. Recently, Bromet et al (13) conducted a one-year follow-up study and reported that job demand and its interaction with co-worker support are important predictors of psychiatric symptoms and broad affective disorders. These few longitudinal studies suggested that job stress is one of the causes of depressive symptoms and, perhaps, depressive disorders. However, such longitudinal studies with only one follow-up period provided limited information because the way the risk of depression due to job stress changes over time is unknown. In particular, what has not been adequately investigated is whether job stress is related to longterm risk for depressive symptoms. In the previous studies, the relative importance of a certain job stress, such as poor intrinsic work rewards or poor social support at the workplace, was assessed only on the basis of the magnitude of the correlations between job stress and depressive symptoms. The temporal course of the 
effects of job stress should be taken into consideration in the assessment of the relative importance of job stress, because some job stress may be chronic or enduring while other job stress may be acute or shorttermed and chronic or enduring job stress is probably a more important risk factor for illness than acute or short-termed job stress.

The present study was carried out to assess the effects of job stress on depressive symptoms over a three-year period among male blue-collar workers in an electrical factory in Japan. The effects of selected sources of job stress on depressive symptoms repeatedly measured each year of the follow-up were examined, initial depressive symptoms and other possible confounders being controlled for.

\section{Subjects and methods}

\section{Subjects}

A total of 1266 full-time employees of an electrical factory in a suburb of Tokyo was surveyed in 1984 (ie, at $T_{0}$ ). A questionnaire concerning background data, job stress, and depressive symptoms was sent to each of the subjects. A total of $1152(91 \%)$ of the workers responded.

Detailed analyses were undertaken for all of the male blue-collar workers aged 20 to 49 years who responded to the survey $(\mathrm{N}=504)$; they consisted of machine operators, assemblers, production inspectors, and mechanics. Four hundred and sixty-eight of the workers completed all of the questions and were followed prospectively for the succeeding three years. The mean age of the subjects was 37.8 (SD 8.6) years. During the follow-up period, they were surveyed once a year with a postal questionnaire and their depressive symptoms were assessed (ie, at $T_{1}, T_{2}$, and $T_{3}$ ). The follow-up rates were 92,90 , and $83 \%$ at $T_{1}, T_{2}$, and $T_{3}$, respectively.

\section{Methods}

Depressive symptoms. Depressive symptoms were measured with the Zung Self-Rating Depression Scale (14). Previous research has found the scale to exhibit acceptable reliability and validity in both Japan and Western countries $(15,16)$. The subjects were asked to complete the scale at $T_{0}, T_{1}, T_{2}$, and $T_{3}$. The coefficient of internal consistency (Cronbach's alpha) was 0.81 for the present subjects. The subjects with scores greater than 48 (ie, mean plus one standard deviation) were defined as "depressed." With the use of this criterion, the prevalences of "depressed" workers were 13.0, 10.5, 9.8, and $11.3 \%$ at $T_{0}, T_{1}, T_{2}$, and $T_{3}$, respectively. There were no significant differences in the prevalence rates across the four surveys (Cochran $Q$ test for $\mathbf{3 7 2}$ subjects who responded to all of the surveys, $\mathrm{P}>0.05$ ).
Predictor variables. Ten measures of job stress or stressors were assessed at $\mathbf{T}_{0}$. Seven scales of perceived job stress were developed on the basis of the results of factor analyses of 17 questions on job stress and were used to measure the psychosocial and physical work environment (17). The job overload scale (4 items) measured the amount of work and frequency of exhaustion after work, work pressure, and thinking about work at home. The poor physical environment scale ( 5 items) was represented by the number of problems experienced regarding temperature, brightness, noise, dust, and bad smell at the workplace. Items on lack of control over workpace and job unsuitability (ie, whether the job was not suitable for a worker's skills and abilities) were classified as one group in the factor analysis. However, the correlation between these items was low (Pearson r, 0.32). Thus the items were used as separate one-item scales measuring lack of control over workpace and job unsuitability. Poor human relations ( 3 items) measured the degree of problems in human relations at the workplace. Complicated machine operation was assessed with a one-item scale inquiring about the degree of complexity of operation required by machines which the subject used. The introduction of new machines and technology to the subject's workplace was also assessed on a one-item scale. One item inquiring about dissatisfaction with work results was not used to avoid overlapping of the content of measures of job stress and reaction to the stress (20).

The coefficients of internal consistency (Cronbach's alpha) for the scales of job overload, poor physical environment, and poor human relations at the workplace were $0.69,0.64$, and 0.60 , respectively. The gamma coefficients for one-year stability of lack of control over workpace and job unsuitability was 0.56 and 0.74 , respectively. No information was available concerning the reliability or stability of the scale on complicated machine operation or the introduction of new technology. The subjects were divided into two groups on the basis of their job stress scores (ie, approximately the upper $25 \%$ and the remaining $75 \%$ ) so that those portions of the sample could be identified that could be considered "higher" or "lower" with respect to a given job stress measure.

Three objective measures of job stress assessed by single questions were as follows: shift work, recent job change (ie, change of position, workplace or job description within the preceding six months), and overtime (ie, hours per month). Overtime was dichotomized into less than and more than 50 (mean 36, SD 19) h per month.

Five covariates were included in certain multivariate analyses: age, marital status, education, type $\mathrm{A}$ behavior, and initial medical treatment. Age was categorized into three groups (ie, 20-29, 30-39, and $40-49$ years of age). Marital status was dichotomized into married and not married. Length of education was dichotomized into less than nine years and nine or more 
years (45 and $55 \%$ of the subjects, respectively). Type A behavior was measured with a five-item scale, the details of which have been described previously (17). Those subjects who had scores greater than the mean plus one standard deviation were defined as having a high tendency toward type A behavior. Medical treatment at $T_{0}$ was assessed by an interview conducted by trained nurses. The subjects were dichotomized on the basis of whether or not they had received medical treatment for any disease at $\mathrm{T}_{0}$.

The proportion of depressive symptoms in each year of the follow-up was compared among the groups classified on the basis of job stress variables by means of the chi-square test with Yates' correction in each of the groups with and without initial depressive symptoms. Binomial regression analysis for relative risk models using general linear interaction modeling (GLIM) (18) was employed to assess the unique effects of each job stress variable on depressive symptoms at $T_{1}, T_{2}$, and $T_{3}$. Depressive symptoms at $T_{0}$, age, marital status, education, medical treatment, and type $A$ were entered into the equation first to control for these factors. Then the 10 job stress variables were entered and eliminated with the use of a backward stepwise procedure to determine the significant contribution to the model. The job stress variable with the smallest t-value (ie, estimated coefficient divided by standard error) was eliminated at each step. The significance of the effect of the variable was assessed with the chisquare approximation to the scaled deviance between models before and after the elimination of the variable (19). The criterion for the inclusion of variables was $\mathrm{P}<0.05$. Relative risk and its $95 \%$ confidence intervals for depressive symptoms of significant job stress variables were calculated on the basis of the standard errors of the coefficients. The GLIM system release 3.77 was used in these analyses (19).

\section{Results}

Among those who were not depressed at $\mathrm{T}_{0}$, the rates of depressed workers were significantly higher for the subjects with higher scores of job unsuitability than for those with the lower scores at $T_{2}$ and $T_{3}$ (table 1). Similarly, the rate was significantly higher for the subjects with higher scores of job overload and lack of control over workpace than for the subjects with the lower scores of these scales at $T_{1}$. The rate was significantly higher for the subjects with higher scores of poor human relations at the workplace than for the subjects with the lower scores at $T_{2}$. Among those who were depressed at $T_{0}$, the rates were not significantly different at any of the follow-ups between the groups classified on the basis of job overload, lack of control over workpace, job unsuitability, or poor human relations at the workplace $(\mathrm{P}>0.05)$. For neither the subjects who were depressed nor those depressed at $\mathbf{T}_{0}$ did the rates significantly differ in any year of the follow-up between the groups classified on the basis of other job stress variables (ie, poor physical environment, complicated machine operation, introduction of new machine technology, shift work, recent job change, or overtime) ( $\mathrm{P}>0.05)$.

The results of the stepwise binomial regression analyses indicated that lack of control over workpace was a significant predictor for depressive symptoms at $T_{1}$ (table 2). Job unsuitability was a significant predictor for depressive symptoms at $T_{2}$ and $T_{3}$. Poor human relations at the workplace were significantly related to

Table 1. Rates of "depressed" workers in the follow-ups ( $T_{1}, T_{2}$ and $T_{3}$ ) by job overload, lack of control over workpace, job unsuitability, and poor human relations at the workplace for the male blue-collar workers who were not depressed and those who were depressed in the initial survey $\left(\mathrm{T}_{0}\right)$.

\begin{tabular}{|c|c|c|c|c|c|c|c|c|c|c|c|c|}
\hline \multirow{3}{*}{ Job stress at $T_{0}$} & \multicolumn{6}{|c|}{ Not depressed at $T_{0}$} & \multicolumn{6}{|c|}{ Depressed at $T_{0}$} \\
\hline & \multicolumn{2}{|c|}{$\begin{array}{c}\text { 1st year } \\
\left(T_{1}\right)\end{array}$} & \multicolumn{2}{|c|}{$\begin{array}{c}\text { 2nd year } \\
\left(\mathrm{T}_{2}\right)\end{array}$} & \multicolumn{2}{|c|}{$\begin{array}{c}\text { 3rd year } \\
\left(\mathrm{T}_{3}\right)\end{array}$} & \multicolumn{2}{|c|}{$\begin{array}{c}\text { 1st year } \\
\left(\mathrm{T}_{1}\right)\end{array}$} & \multicolumn{2}{|c|}{$\begin{array}{c}\text { 2nd year } \\
\left(T_{2}\right)\end{array}$} & \multicolumn{2}{|c|}{$\begin{array}{c}\text { 3rd year } \\
\left(T_{3}\right)\end{array}$} \\
\hline & $\mathrm{N}$ & $\%$ & $\mathrm{~N}$ & $\%$ & $\mathrm{~N}$ & $\%$ & $\mathbf{N}$ & $\%$ & $\mathrm{~N}$ & $\%$ & $\mathbf{N}$ & $\%$ \\
\hline \multicolumn{13}{|l|}{ Job overload } \\
\hline $\begin{array}{l}\text { Higher } \\
\text { Lower }\end{array}$ & $\begin{array}{l}108 \\
267\end{array}$ & $\begin{array}{c}10^{\star \star} \\
3\end{array}$ & $\begin{array}{l}104 \\
259\end{array}$ & $\begin{array}{l}7 \\
5\end{array}$ & $\begin{array}{r}96 \\
240\end{array}$ & $\begin{array}{l}9 \\
5\end{array}$ & $\begin{array}{l}31 \\
25\end{array}$ & $\begin{array}{l}42 \\
52\end{array}$ & $\begin{array}{l}31 \\
25\end{array}$ & $\begin{array}{l}39 \\
40\end{array}$ & $\begin{array}{l}32 \\
21\end{array}$ & $\begin{array}{l}41 \\
52\end{array}$ \\
\hline \multicolumn{13}{|c|}{ Lack of control over workpace } \\
\hline $\begin{array}{l}\text { Higher } \\
\text { Lower }\end{array}$ & $\begin{array}{r}75 \\
300\end{array}$ & $\begin{array}{c}11^{*} \\
4\end{array}$ & $\begin{array}{r}74 \\
289\end{array}$ & $\begin{array}{l}7 \\
5\end{array}$ & $\begin{array}{r}50 \\
286\end{array}$ & $\begin{array}{r}10 \\
5\end{array}$ & $\begin{array}{l}18 \\
38\end{array}$ & $\begin{array}{l}56 \\
42\end{array}$ & $\begin{array}{l}18 \\
38\end{array}$ & $\begin{array}{l}50 \\
34\end{array}$ & $\begin{array}{l}19 \\
34\end{array}$ & $\begin{array}{l}53 \\
41\end{array}$ \\
\hline \multicolumn{13}{|l|}{ Job unsuitability } \\
\hline $\begin{array}{l}\text { Higher } \\
\text { Lower }\end{array}$ & $\begin{array}{l}102 \\
273\end{array}$ & $\begin{array}{l}9 \\
4\end{array}$ & $\begin{array}{l}101 \\
262\end{array}$ & $\begin{array}{c}10^{*} \\
3\end{array}$ & $\begin{array}{r}91 \\
245\end{array}$ & $\begin{array}{c}14^{\star \star} \\
3\end{array}$ & $\begin{array}{l}33 \\
23\end{array}$ & $\begin{array}{l}48 \\
43\end{array}$ & $\begin{array}{l}32 \\
24\end{array}$ & $\begin{array}{l}41 \\
38\end{array}$ & $\begin{array}{l}32 \\
21\end{array}$ & $\begin{array}{l}50 \\
38\end{array}$ \\
\hline \multicolumn{13}{|c|}{ Poor human relations at the workplace } \\
\hline $\begin{array}{l}\text { Higher } \\
\text { Lower }\end{array}$ & $\begin{array}{r}76 \\
299\end{array}$ & $\begin{array}{l}7 \\
5\end{array}$ & $\begin{array}{r}75 \\
288\end{array}$ & $\begin{array}{c}11^{* *} \\
4\end{array}$ & $\begin{array}{r}70 \\
266\end{array}$ & $\begin{array}{l}4 \\
6\end{array}$ & $\begin{array}{l}24 \\
32\end{array}$ & $\begin{array}{l}58 \\
38\end{array}$ & $\begin{array}{l}23 \\
33\end{array}$ & $\begin{array}{l}52 \\
30\end{array}$ & $\begin{array}{l}23 \\
30\end{array}$ & $\begin{array}{l}48 \\
43\end{array}$ \\
\hline
\end{tabular}


Table 2. Significant job stress variables for depressive symptoms in the follow-ups $\left(T_{1}, T_{2}\right.$, and $\left.T_{3}\right)$ among male blue-collar workers: binomial regression for risk ratios using backward elimination with eight job stress variables by GLIM, controlling for depressive symptoms at $T_{0}$ and five covariates. ${ }^{a}$

\begin{tabular}{|c|c|}
\hline $\begin{array}{l}\text { Follow-up } \\
\text { period }\end{array}$ & Significant job stress variable ${ }^{b}$ \\
\hline $\begin{array}{l}\text { ine year }\left(T_{1}\right) \\
V=431)\end{array}$ & $(1.71,1.10-2.6$ \\
\hline $\begin{array}{l}\text { wo years }\left(T_{2}\right) \\
V=419)\end{array}$ & $\begin{array}{l}\text { Job unsuitability }(1.85,1.28-2.68) \\
\text { Poor human relations at the workplace } \\
(1.94,1.17-3.20)\end{array}$ \\
\hline irs $\left(T_{3}\right)$ & Job unsuitabili \\
\hline \multicolumn{2}{|c|}{$\begin{array}{l}\text { Eight job stress variables, depressive symptoms at } T_{0} \text {, and } \\
\text { five covariates (age, marital status, education, medical treat- } \\
\text { ment, and type A) were entered into the equations first; then } \\
\text { eight job stress variables were dropped stepwise using back- } \\
\text { ward elimination (inclusion criteria: } P<0.05 \text { ). } \\
\text { Estimated risk ratio and } 95 \% \text { confidence interval in paren- } \\
\text { theses. }\end{array}$} \\
\hline
\end{tabular}

depressive symptoms at $T_{2}$. When similar analyses were made for the $\mathbf{3 7 5}$ subjects who were not depressed at $T_{0}$, job overload was selected as a variable significantly related to depressive symptoms at $T_{1}$ $(\mathrm{P}<0.05)$. The estimated risk ratios were $3.66[95 \%$ confidence interval $(95 \% \mathrm{CI}) 1.52-8.80$ ]. Job unsuitability was significantly associated with depressive symptoms at $T_{2}$ and $T_{3}(P<0.05)$. The estimated risk ratios were $2.75(95 \% \mathrm{CI} 1.15-6.55)$ and $3.06(95 \%$ CI 1.24-7.53), respectively. No other job stress variable was significantly associated with depressive symptoms at $T_{1}, T_{2}$, or $T_{3}(P>0.05)$. In none of these analyses were the interaction terms of any combinations of two job stress variables selected as a significant predictor of depressive symptoms $(P>0.05)$.

During the three-year follow-up period, $28 \%$ of the subjects reported to have changed either their position, workplace, or job content. The rates of job change were not significantly different between the groups classified on the basis of any of the initial 10 job stress variables (chi-square test with Yates' correction, $\mathrm{P}>0.05$ ).

\section{Discussion}

In the present study, the results of binomial regression analyses indicated that job unsuitability and poor human relations at the workplace were significant predictors for depressive symptoms in the two- or three-year follow-up. It is suggested that these job stressors are important risk factors for long-lasting depressive symptoms among Japanese male blue-collar workers. In contrast, job overload and lack of control over workpace were significantly associated with depressive symptoms only at the one-year follow-up. The present study failed to indicate that job overload or lack of control over workpace is a risk factor for long-lasting depressive symptoms.
Job unsuitability was a significant predictor for depressive symptoms in the two- and three-year followups. An important risk factor for long-lasting depressive symptoms might be a job that is not suitable for a worker's skills and abilities. The results are consistent with previous cross-sectional studies which reported that underutilization of skills (3) is an important risk factor for depressive symptoms. The results are also consistent with the higher percentage of job unsuitability observed for major depressive patients in our previous study (21).

The job change rate during the follow-up period was not significantly associated with any of the eight job stress variables. Thus the present results are not attributable to self-selection of job by workers suffering from job unsuitability. The following explanations are possible: (i) job unsuitability may last for a longer period because it mainly depends on the relationship between workers' skills and abilities and job contents, while other job stressors, such as job overload, may change more over time according to changes in situations at the workplace; (ii) it may be more difficult for workers to cope with job unsuitability than with other job stressors, as suggested by a previous finding (22) that the effects of work load on depression is more likely to be buffered by support from family members than those of role ambiguity, future ambiguity, and skill underutilization; and (iii) the present results might be explained by the theory of learned helplessness recently introduced to work settings (23). Such attributional style learned by workers suffering from job unsuitability could cause long-term depressive symptoms.

Human relations at the workplace were also found to be a significant predictor of depressive symptoms at the two-year follow-up. The results are consistent with the findings from previous cross-sectional studies $(4,7,8)$ and a one-year follow-up study (13).

Job overload significantly correlated with depressive symptoms at the one-year follow-up. This finding agrees with the finding in a previous one-year follow-up study (13). The significant association between lack of control over workpace and depressive symptoms at the one-year follow-up is consistent with a cross-sectional observation (6). However, in the present study, these two job stressors did not seem to be risk factors for long-lasting depressive symptoms. In addition the effect of job overload was not clear in the case of initially depressed subjects. Such an interactive phenomenon might be attributable to "saturation" effects (20). Job overload may not be related to an increase in depressive symptoms once the symptoms increase to a certain level.

Unfortunately, change of job stress over time was not assessed in the present study. It is not clear whether depressive symptoms over time are caused by sustained job stress or whether depressive symptoms once evoked by job stress tend to continue for a long period even after job stress itself declines. Depressive symptoms also have a remittent nature. A previous survey of a 
nonpatient working population showed that the mean duration of depressive symptoms was less than eight months (24). The present results do not necessarily suggest that job stress is related to the formation of a group of workers with continuous higher depressive symptoms over years. In the present study, in which depressive symptoms were assessed once a year, it was not clear whether job stress led to a chronic episode of depressive symptoms over years or to a sustained risk for frequent and intermittent depressive symptoms. More frequent (eg, once every six months) and repeated observation of both job stress and depressive symptoms is needed to clarify these issues.

The following methodological weakness should also be considered in the interpretation of the results. First, none of the objective job stress measures significantly correlated with depressive symptoms. The association between subjective measures of job stress and outcomes might be misleading because of response tendencies. Second, the present study did not include measures of personalities other than type $A$, which might be confounding in the association between job stress and depressive symptoms. Third, the reliability of the job stress scales used in the present study was moderate or not adequately examined. Lack of a significant association between the scales and depressive symptoms could be attributable to a low reliability of the scales. The present results should be examined with a more reliable measure. Finally, the job stress model adopted in the present study included only a limited number of the proposed theoretical models $(1,4,12)$. To explain the possible psychological mechanisms attributable to the present results, further longitudinal study is needed to examine temporal relationships among job stressor, stress reaction, and health outcome, using both subjective and objective measures and considering several intervening variables. A recent cross-cultural study pointed out that human relations at the workplace are more important for psychological symptoms among Japanese managers than among American managers (25). In the present study, Japanese blue-collar workers seemed to be affected by job stresses similar to those previously reported in Western countries. However, some characteristics of Japanese factories, such as a tendency for workers to be employed for almost all of their worklife in the same company with few chances to change job or employment (26), may lead to long-term job unsuitability. Further studies are needed to replicate the present results and to permit an extension of these findings to female workers and to workers of other occupations in Japan, as well as to other countries.

\section{Acknowledgments}

This study was completed while Dr Kawakami was at The University of Texas School of Public Health. Support for this research was provided in part by the So- cial Psychiatry Research Group at The University of Texas School of Public Health.

Appreciation is expressed to the Director, RE Roberts, PhD. Thanks are also due to CR Roberts, $\mathrm{PhD}$, for her valuable suggestions during the preparation of this manuscript, to Professor ES Lee of the University of Texas School of Public Health for his suggestions on the statistical analysis, and to Dr T Arakawa and Ms S Shoji at the Hitachi Health Care Center for their assistance with the data collection.

\section{References}

1. Kasl SV. Mental health and work environment. J Occup Med 1973;15:509-18.

2. International Labour Office (ILO). Psychosocial factors at work. Geneva: ILO, 1986. (Occupational health and safety series; no 56. .)

3. Margolis BL, Kroes WH, Quinn RP. Job stress: an unlisted occupational hazard. J Occup Med 1974;16: 659-61.

4. Caplan RD, Cobb C, French JRP. Job demand and worker health. Washington, DC: US Government Printing Office, 1975. (NIOSH research report; no 75-160.)

5. Ilfeld FW. Current social stressors and symptoms of depression. Am J Psychiatry 1977;134:161-6.

6. Karasek RA. Job demands, job decision latitude, and mental strain: implications for job-redesign. Adm Sci Q 1979;24:285-308.

7. Billings AG, Moos RH. Work stress and the stressbuffering roles of work and family resources. J Occup Behav 1982;3:215-32.

8. Broadbent DE. The clinical impact of job design. $\mathrm{Br} \mathbf{J}$ Clin Psychol 1985;24:33-44.

9. Revicki DA, May HJ. Occupational stress, social support, and depression. Health Psychol 1985;4:61 - 77.

10. Dohrenwend BP, Shrout PE, Egri G, Mendelsohn FS. Nonspecific psychological distress and other dimensions of psychopathology. Arch Gen Psychiatry 1980;37: 1229-36.

11. Roberts RE. Epidemiological issues in measuring preventive effects. In: Munoz RF, ed. The prevention of depression: research directions. Washington, DC: Hemisphere Publishing, 1987:45-75.

12. House JS, McMichael AJ, Wells JA, Kaplan BH, Landerman LR. Occupational stress and health among factory workers. J Health Soc Behav 1979;20:139-60.

13. Bromet EJ, Dew MA, Parkinson DK, Schulberg HC. Predictive effects of occupational and marital stress on the mental health of a male workforce. J Organ Behav 1988;9:1-13.

14. Zung WWK. A self-rating depression scale. Arch Gen Psychiatry 1965;12:63-70.

15. Zung WWK. A cross-cultural survey of symptoms in depression. Am J Psychiatry 1969:126:154-9.

16. Zung WWK. From art to science: the diagnosis and treatment of depression. Arch Gen Psychiatry 1973;29: 328-37.

17. Kawakami N, Haratani T, Kaneko T, Araki S. Perceived job-stress and blood pressure increase among Japanese blue-collar workers: one year follow-up study. Ind Health 1989:27:71-81.

18. Wacholder S. Binominal regression in GLIM: estimating risk ratios and risk differences. Am J Epidemiol 1986; 123:174-184.

19. Payne CD, ed. The GLIM system release 3.77 manual. Oxford: Numerical Algorithms Group, 1985.

20. Kasl SV. Stress and disease in the workplace: a methodological commentary on the accumulated evidence. In: 
Cataldo MF, Coates TJ, ed. Health and industry: a behavioral medicine perspective. New York, NY: John Wiley \& Sons, 1986:52-85.

21. Kawakami N, Araki S, Kawashima M. Effects of job stress on occurrence of major depression in Japanese industry: a case-control study nested in a cohort study. J Occup Med 1990;32:722-25.

22. LaRocco JM, House JS, French JRP. Social support, occupational stress, and health. J Health Soc Behav 1980;21:202-18.

23. Lennerlöf L. Learned helplessness at work. Int J Health Serv 1988;18:207-22.

24. Barrett J, Hurst MW, DiScala C, Rose RM. Prevalence of depression over a 12-month period in a nonpatient population. Arch Gen Psychiatry 1978;35:741 -4.

25. DeFrank RS, Ivancevich JM, Schweiger DM. Job stress and mental well-being: similarities and differences among American, Japanese, and Indian managers. Behav Med 1988;14:160-70.

26. Lincoln JR, Kalleberg AL. Work organization and workforce commitment: a study of plants and employees in the US and Japan. Am Sociol Rev 1985;50:738-60.

Received for publication: 3 September 1990 